\section{Effects of Three Hotcap Designs on Temperature and Tomato Transplant Development}

\author{
G.E. Welbaum ${ }^{1}$ \\ Department of Horticulture, Virginia Polytechnic Institute and State University, \\ Blacksburg, VA 24061-0327
}

Additional index words. Lycopersicon esculentum, frost protection, plant covers

\begin{abstract}
Hotcaps are covers used to protect individual plants from suboptimal temperatures. Temperature, solar energy, photosynthetic photon flux (PPF), and tomato (Lycopersicon esculentum Mill.) transplant development were compared for three hotcap designs: 3.8-liter, opaque plastic jugs (PJs); 24-cm-tall wax paper (WP); and Wall-OWater water-filled plastic teepees (PTs). The average solar energy inside the hotcaps was $57.3 \%, 67.6 \%$, and $28.9 \%$ of full sun at midday and PPF was $44.7 \%, 49.7 \%$, and $43.8 \%$ of full sun at midday for WP, PJs, and PTs, respectively. The rate of temperature decline in a growth chamber was fastest for PJs and slowest for PTs. In the field, air and soil temperatures inside hotcaps were higher than ambient during sunny periods and essentially the same during cloudy weather. The overall mean and mean maximum daily soil and air temperatures for all hotcaps were higher than ambient. PTs had the highest minimum daily soil and air temperatures-2.0 and 1.9C above ambient, respectively. The meantime to first ripe fruit was reduced by 10.7 days for PTs, 6.7 days for WP, and increased by 5 days for PJs compared to noncovered plants. Plants grown under hotcaps weighed less and produced fewer fruit on the first cluster. PJs could not maintain night air temperatures above ambient and were not effective hotcaps.
\end{abstract}

Using rowcovers to protect vegetables from suboptimal temperatures has increased recently (Wells, 1990; Wells and Loy, 1986). However, some commercial growers and gardeners continue to use individual plant covers (hotcaps) for frost protection and to hasten maturity. Although the effects of rowcovers on plant growth and development have been investigated widely, few studies have compared the efficacy of hotcap designs. In a previous study, rigid plastic hotcaps provided less frost protection than wax paper (WP) (Zink, 1954). Muskmelon (Cucumis melo L.) plants started under either plastic or WP hotcaps matured at the same rate and produced the same total yield (Zink, 1954). Tomato transplants initially covered by 0.25 -liter plastic cups had the same early yield and lower total yield compared to noncovered plants (Taber, 1983).

New hotcap designs reputedly have superior heat-retention characteristics and may provide greater frost protection than those previously tested. One new design uses a series of fused, clear, water-filled plastic tubes to form a stable plastic teepee (PT) around the plant. Theoretically, the water in each hotcap is heated by solar energy during the day, and, at night,

Received for publication 2 Nov. 1992. Accepted for publication 14 Apr. 1993. The trade or brand names given are supplied only for the purpose of information and do not constitute an endorsement or a recommendation over other brands or companies. The cost of publishing this paper was defrayed in part by the payment of page charges. Under postal regulations, this paper therefore must be hereby marked advertisement solely to indicate this fact. ${ }^{1}$ Assistant Professor. the warm water maintains the hotcap temperature above ambient. Although anecdotal information suggests that water-filled hotcaps are effective (Bilderback, 1988), scientific data are lacking. Opaque plastic jugs (PJs) are used widely as hotcaps because they are readily available and inexpensive. However, their effectiveness has not been studied scientifically. In this study, 4-week-old tomato transplants were planted under 3.8-liter PJ, water-filled PT, and WP hotcaps 6 weeks before the frostfree date in 2 years to determine which design provided the greatest frost protection and best environment for tomato transplant development.

'Early Girl' tomato plants (Burpee Seed Co., Warminster, $\mathrm{Pa}$.) were grown in a greenhouse in transplant trays with $3.2 \times 3.2 \times 4.5$ $\mathrm{cm}$ cells. Four-week-old plants were set in a field near Blacksburg, Vs., during the first week of Apr. 1991 and 1992. The herbicide $N$ (phosphonomethyl)glycine (glyphosate) (Monsanto, St. Louis) was applied during field preparation and provided adequate weed control until late in the season when plots were weeded by hand. Fertilizer $(10 \mathrm{~N}-4.3 \mathrm{P}-8.3 \mathrm{~K})$ at $100 \mathrm{~kg} \cdot \mathrm{ha}^{-1}$ was row-banded at transplanting. A drench that combined $9 \mathrm{~N}-19.4 \mathrm{P}-12.5 \mathrm{~K}$ fertilizer $\left(4 \mathrm{~g} \cdot \operatorname{liter}^{-1}\right)$ and the insecticide $O-O$ diethyl $O$ - [6-methyl-2-(1-methylethyl)-4pyrimidinyl] phosphorothioate (diazinon) $(0.7$ g.liter $\left.{ }^{-1}\right)$ was applied at $250 \mathrm{ml} / \mathrm{plant}$ at transplanting. A Bravo-Ridomil 81W \{9\% N-(2,6dimethylphenyl) -N-(methoxyacetyl) -DL-alanine methyl ester (metalaxyl) and $72 \%$ tetrachloroisophthalonitrile (chlorothalonil)\} ing season as a precaution. Plants were wafungicide was applied during the 1992 grow- tered uniformly as required using a small, hand-held container.

Three hotcap designs were studied: 1) 3.8liter, opaque PJs (Kroger Co., Cincinnati) with the cam and bottoms removed; 2) 24-cm-tall WP (Wetzel Seed Co., Harrisonburg, Vs.); and 3) water-filled PTs (Wall-O-Water; TerraCopia, Salt Lake City). The cylinders of PTs were filled with $400 \mathrm{ml}$ water in 1991 and $2.5 \% \mathrm{NaOCl}$ in 1992 . Water was added periodically to maintain a minimum level during the growing season, but excess rainwater was not removed. WP caps were secured by burying the lip under soil. PJs were attached with wire to 2-cm-thick bamboo stakes grounded 5 $\mathrm{cm}$ from the base of each plant. When the threat of frost had passed, PJs were removed, WP was slit open on top, and PTs were spread at the top and narrowed at the base to provide additional room for growth.

In 1991 and 1992, air temperatures were measured by 2-mm-diameter thermocouples (type T; Omega Engineering, Stamford, Corn.) attached to thin wooden stakes $5 \mathrm{~cm}$ above the soil, $5 \mathrm{~cm}$ from the center of each plant, and 1 $\mathrm{cm}$ from each stake to shade the junction from direct sunlight. In 1991, soil temperatures were recorded by the same kind of thermocouples buried $3 \mathrm{~cm}$ deep and $5 \mathrm{~cm}$ from the base of each plant. Thermocouple wires were buried between each plant, and the data logger (Polycorder; Omnidata, Logan, Utah) was set to scan at 30-min intervals. Daily mean, minimum, and maximum temperatures were averaged for 10 days in late April to obtain overall mean temperatures. Inside the hotcaps under clear conditions on 26 Mar. 1991, solar energy (watts per square meter) was measured using a pyranometer (model LI-200SB; LI-COR, Lincoln, Neb.), and photosynthetic photon flux (PPF) (micromoles per square meter per second) was measured using a quantum sensor (model LI-190SB; LI-COR). Data were recorded with a data logger (model CR-10; Campbell Scientific, Logan, Utah) with a scan rate of 1 rein, averaged every $5 \mathrm{~min}$. To determine the rate of heat loss under controlled conditions, each hotcap design was placed in a growth chamber (model E-54B; Percival, Boone, Iowa) on 5-cm-deep vermiculite. The temperature of the air and vermiculite inside each hotcap was recorded as the growth chanber was lowered from 30 to $5 \mathrm{C}$ in $1 \mathrm{~h}$.

The number of days to the frost open flower was determined based on when the corolla was first visible. Plant height at the time of the first open flower was measured from the soil to the highest point on the youngest visible leaf. The number of days to the first ripe fruit was determined based on when fruit were solid red. All fruit on the first cluster of each plant were harvested, counted, and weighed when the first fruit was ripe to determine the total number of fruit set and total fruit weight on the first cluster. Entire plants, excluding roots, were harvested on 28 July and dried at $70 \mathrm{C}$ for 5 days to determine dry weight.

Plants were spaced $1 \mathrm{~m}$ apart in a completely randomized design with four replications per treatment. Analysis of variance (ANOVA) and linear regression were per- 
formed using the CoStat program (CoHort Software, Berkeley, Calif.). Mean temperature data in 1991 and 1992 were analyzed for 10 days in late April using a split-plot design, with hotcaps assigned to subplots, years to main plots, and days to blocks. Temperature time courses in Fig. 1 were linear when plotted as log temperature vs. time, thus allowing the rate of temperature decline to be analyzed by comparing the slopes of regression lines.

An effective hotcap transmits sufficient solar energy for photosynthesis and to warm the air inside, but not so much that plants are damaged by overheating. Hotcaps also must retain sufficient heat during the night to protect plants from low-temperature injury. The ability of each hotcap design to protect the plants against a sudden decrease in temperature was tested in a growth chamber. The rate of decline was fastest for PJs, slightly less for WP, and slowest for PTs (Fig. 1).
All hotcap designs transmitted $<70 \%$ of the available solar energy, although PTs transmitted less solar energy than WP or PJs (Table 1). The PPF inside PJs was higher than inside WP or PTs, and the values for all three hotcap designs were $<50 \%$ of full sun (Table 1 ).

Soil temperatures depended on the amount of irradiance. During overcast periods, temperatures of covered and noncovered soil were virtually the same (Fig. 2A). On sunny days, maximum soil temperatures were as much as $5 \mathrm{C}$ higher than ambient under PJs but only 2 to $3 \mathrm{C}$ higher under PTs and WP (Fig. 2A). Under clear skies, ambient soil temperature fell rapidly from 14 to $\approx 6 \mathrm{C}$ during the afternoon and early evening (Fig. 2A). Because of the poor heat-retention characteristics of PJs, the soil temperature beneath PJs dropped from 19 at midday to 7C, the lowest of any hotcap design. Soil temperatures for WP and PTs declined rapidly after sunset, paralleling ambient but

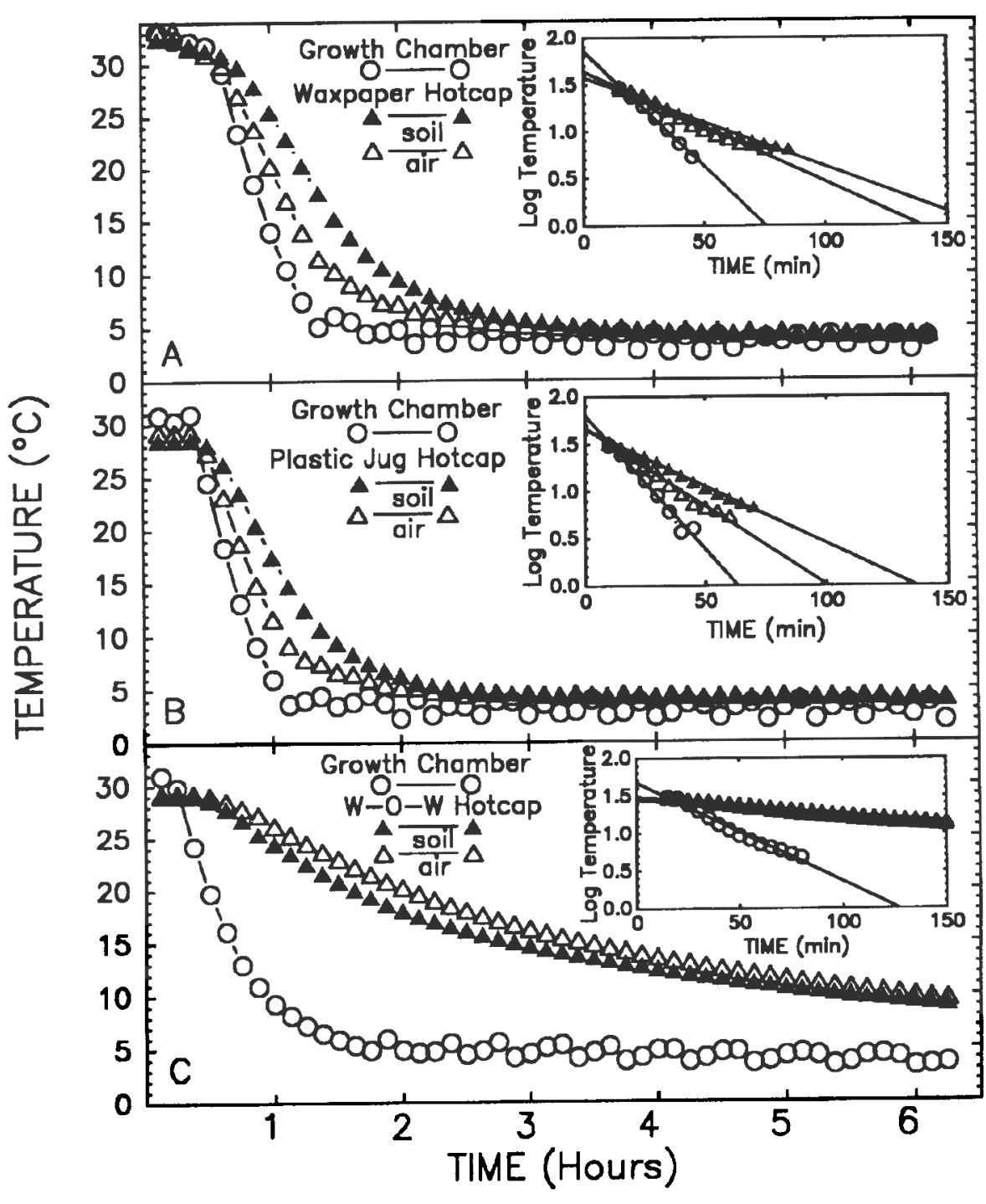

Fig. 1. Hotcap air and soil temperature changes in a growth chamber rapidly cooled from 30 to $5 \mathrm{C}$. Insets show the same data plotted as log temperature vs. time, with linear regressions through the data. The slopes $( \pm \mathrm{SE})$ of the log regression lines $\left(r^{2} \geq 0.97\right)$ areas follows: air outside WP, $-0.02 \times\left( \pm 9.7 \times 10^{-4}\right)$; air inside WP, $-0.01 \mathrm{x}\left( \pm 2.7 \times 10^{-4}\right)$; vermiculite (soil) inside WP, $-0.01 \times\left( \pm 5.1 \times 10^{-4}\right)$; air outside PJs, $-0.03 \mathrm{x}\left( \pm 1.7 \times 10^{-3}\right)$; air inside PJs, $0.01 \mathrm{x}\left( \pm 2.3 \times 10^{-4}\right)$; soil inside PJs, $-0.02 \mathrm{x}\left( \pm 6.9 \times 10^{-4}\right)$; air outside PTs, $-0.01 \mathrm{x}\left( \pm 5.2 \times 10^{-4}\right)$; air inside PTs, $-2.1 \times 10^{-3} \mathrm{x}\left( \pm 5.2 \times 10^{-5}\right)$; soil inside PTs, $-2.2 \times 10^{-3} \mathrm{x}( \pm 2.4$ $\left.\times 10^{-5}\right)$. The experiment was replicated five times. One representative cycle for each hotcap design is shown.
Table 1. Solar energy and photosynthetic photon flux (PPF) at $1100 \mathrm{HR}$ on 26 Mar. 1991 near Blacksburg, Va. Each value represents the average of five measurements.

\begin{tabular}{lcr}
\hline \hline Hotcap & Solar energy & PPF \\
\hline \multicolumn{3}{r}{ Percentage of full sunlight } \\
Noncovered $^{\text {Z }}$ & 100.0 & 100.0 \\
Plastic jug & 67.6 & 49.7 \\
Plastic teepee & 28.9 & 43.8 \\
Wax paper & 57.3 & 44.7 \\
$\mathrm{~L} \mathrm{~S} \mathrm{D}_{0.05}$ & 6.8 & 3.2 \\
\hline
\end{tabular}

${ }^{2}$ Solar energy $=1212 \mu \mathrm{mol} \cdot \mathrm{m}^{-2} \cdot \mathrm{s}^{-1}, \mathrm{PPF}=170 \mathrm{~W} \cdot \mathrm{m}^{-2}$.

remaining $\approx 2.5 \mathrm{C}$ higher during the night. On a clear morning, ambient soil temperatures initially increased more rapidly than those of covered soils, and, from 0700 to $0800 \mathrm{HR}$, all temperatures were similar (Fig. 2A). As the morning progressed, covered soils warmed more rapidly and were at least $2 \mathrm{C}$ higher than ambient at midday.

The overall mean, mean minimum, and mean maximum soil temperatures for all hotcaps were higher than ambient (Table 2). Overall mean soil temperatures were highest for PTs and lower for PJs and WP. WP and PTs led to higher mean minimum soil temperatures than PJs. The mean maximum soil temperature was highest for PJs. Overall, PTs were the most effective hotcaps for increasing temperatures near the soil surface.

Daily fluctuations of air temperature inside the hotcaps were greater than those for soil. On a cloudy day in 1991, air temperatures typically were only 2 or $3 \mathrm{C}$ above ambient air temperatures inside PTs and WP were slightly higher than those inside PJs (Fig. 2B). However, on a sunny day, air temperatures inside WP were as much as $18 \mathrm{C}$ higher than ambient, while those inside PJs and PTs were 13 to $15 \mathrm{C}$ higher (Fig. 2B). The minimum air temperature inside PJs on a clear night following a sunny day was nearly identical to ambient (Fig. 2B). Air temperatures inside WP and PTs generally were 1 or $2 \mathrm{C}$ higher than ambient during the night. Ambient air temperatures increased rapidly after sunrise, and, by 0800 $\mathrm{HR}$, air temperatures for all treatments were nearly identical. As the morning progressed, ambient air temperatures and those inside PTs lagged behind those inside other hotcaps until late morning (Fig. 2B). On a cloudy evening following a sunny day, there was essentially no air temperature difference among treatments (Fig. 2B).

Air temperatures inside hotcaps in 1992 were similar to those in 1991. WP led to the highest maximum air temperature on a typical sunny day (Fig. 3). The maximum air temperatures inside PJs and PTs typically were 5C cooler than those inside WP. During the evening, air temperatures inside PJs declined more rapidly than those inside WP or PTs and were the same as ambient by early morning (Fig. 3). During the night, air temperatures inside PTs remained $2.5 \mathrm{C}$ warmer than ambient, compared to $\approx 1 \mathrm{C}$ warmer than those inside WP. As conditions changed to overcast during the afternoon, temperatures dropped rapidly (Fig. 3). During the overcast evening that followed, the minimum temperature for 
all treatments was about the same (Fig. 3).

An ANOVA of mean air temperatures revealed differences among hotcaps and years for all variables, but there was no hotcap $\times$ year interaction. The overall mean air temperature inside all hotcaps was higher than ambient (Table 2). WP and PTs produced higher overall mean air temperatures than PJs (Table 2).

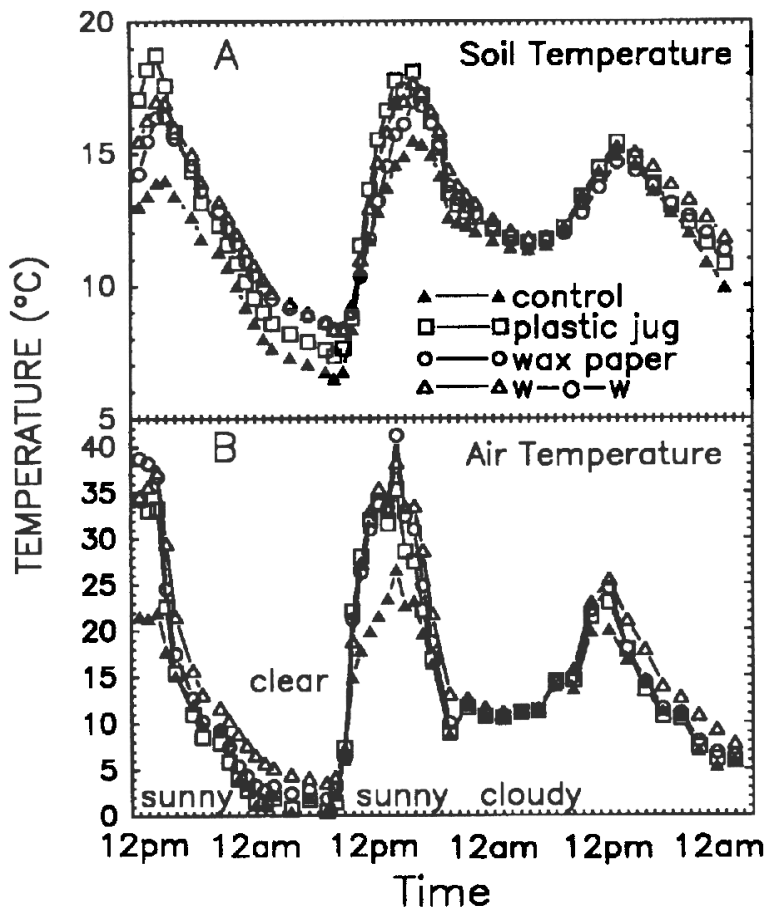

Fig. 2. Soil (A) and air(B) temperature time courses in Apr. 1991. Each point represents one A representative time course is shown.

Table 2. Mean air and soil temperatures near Blacksburg, Va., for 10 days in late April.

\begin{tabular}{|c|c|c|c|c|c|c|}
\hline \multirow[b]{3}{*}{ Hotcap } & \multicolumn{6}{|c|}{ Mean temp ${ }^{2}$} \\
\hline & \multicolumn{3}{|c|}{ Soil (1991) } & \multicolumn{3}{|c|}{ Air (1991-92) } \\
\hline & $\begin{array}{c}\text { Mean } \\
\text { min }\end{array}$ & $\begin{array}{c}\text { Overall } \\
\text { mean }\end{array}$ & $\begin{array}{c}\text { Mean } \\
\max \end{array}$ & $\begin{array}{c}\text { Mean } \\
\text { min }\end{array}$ & $\begin{array}{c}\text { Overall } \\
\text { mean }\end{array}$ & $\begin{array}{c}\text { Mean } \\
\max \end{array}$ \\
\hline Noncovered & 11.3 & 14.8 & 17.4 & 6.0 & 12.7 & 22.0 \\
\hline Plastic jug & 12.1 & 15.9 & 19.8 & 5.8 & 15.0 & 29.5 \\
\hline Wax paper & 12.9 & 15.9 & 18.4 & 6.6 & 16.6 & 33.5 \\
\hline Plastic teepee & 13.3 & 16.6 & 19.4 & 7.9 & 17.0 & 30.5 \\
\hline $\mathrm{LS} \mathrm{D}_{0.05}$ & 0.5 & 0.6 & 1.0 & 0.5 & 0.5 & 1.3 \\
\hline
\end{tabular}

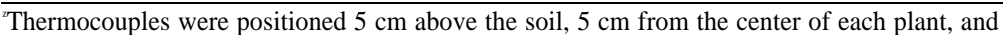
$1 \mathrm{~cm}$ from each stake or buried $3 \mathrm{~cm}$ deep and $5 \mathrm{~cm}$ from the base of each plant.

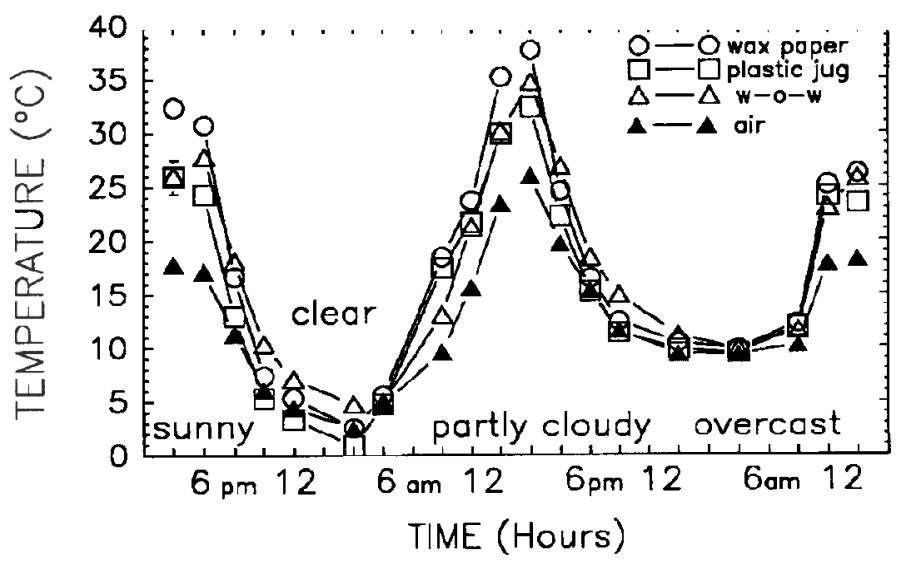

Fig. 3. Air temperatures during clear and partly cloudy weather in Apr. 1992. Each point is an average of three measurements. The SE is displayed when values are larger than the symbols. A representative temperature time course is shown.

WP led to the highest mean maximum air temperature $-11.5 \mathrm{C}$ higher than ambient; however, WP did not retain heat best at night, and the mean minimum temperature inside WP was only $0.6 \mathrm{C}$ above ambient (Table 2 ). A previous study showed that the minimum air temperature inside WP was 1 to $2 \mathrm{C}$ above ambient on a clear night (Zink, 1954). The mean minimum temperature inside PJs was the same as ambient (Table 2). The minimum night temperature inside rigid plastic hotcaps similar in design to PJs also was the same as ambient in an earlier study (Zink, 1954). The overall mean minimum air temperature inside PTs was 1.9C higher than ambient, the highest of any hotcap (Table 2).

Noncovered plants were killed by frost on 3 Apr. 1991. A frost in late Apr. 1991 damaged the upper leaves of plants protected by WP and PJs, but did not damage plants covered by PTs. Plants developing inside closed PTs were succulent and grew poorly until the tops were opened after the threat of frost had passed. The first fruit from PTs matured 78 days after transplanting.

In 1992, there was no frost after plants were set in the field on 1 Apr. Plants remained covered for 47 days due to cool weather, and pollination of the first cluster occurred inside closed hotcaps. All hotcaps were opened on the same date, and harvesting ripe fruit began in late June, 4 to 5 weeks later.

Plant height at the time of the first open flower, days to the first ripe fruit, number of fruit set on the first cluster, total fruit weight on the first cluster, and plant dry weights at first harvest were affected significantly (Table 3 ). Plants inside hotcaps were succulent, tall, spindly (Table 4), and had poor coloration. Noncovered plants were shorter at flowering, set more fruit on the first cluster, had higher dry weights, and were a darker green than plants grown under hotcaps (Table 4). The differences observed between covered and noncovered plants were due, in part, to the low light transmittance of the hotcaps and overcast conditions in 1992. However, the relative humidity inside hotcaps was constantly near $100 \%$, as water condensed on the inside walls at night and did not evaporate completely during the day. The constant high humidity undoubtedly contributed to the poor plant development inside hotcaps.

Tomato fruit development is linked closely to the accumulation of degree days, which for tomato occurs at $>10 \mathrm{C}$ (Gent, 1990). The fist fruit ripened 10.7 and 6.7 days earlier in PTs and WP, respectively, compared to noncovered plants, because the higher mean air temperatures inside these hotcaps accelerated degreeday accumulation (Table 2). The mean number of days to first ripe fruit for PJs was 5 days longer than for noncovered plants, because some plants set no fruit on the first cluster. Overall, the number of fruit set on the first cluster of plants started under hotcaps was about half that of noncovered plants (Table 4). The lack of air movement inside closed hotcaps may have resulted in poor pollination of the first cluster (Table 4). The fruit set on covered plants also may have been inhibited by tem- 
Table 3. Mean squares for seven variables comparing 'Early Girl' tomato transplants grown under three types of hotcaps in 1992.

\begin{tabular}{lcr}
\hline \hline Variable & Hotcaps & Error \\
\hline Days to first flower & 39.6 & 24.5 \\
Plant height at first flower (cm) & $49.9^{* * *}$ & 4.2 \\
Days to first ripe fruit & $201.6^{*}$ & 42.5 \\
Weight of first ripe fruit (g) & 1158.1 & 1078.1 \\
Number of fruit set on first cluster & $6.6^{*}$ & 1.6 \\
Total weight of fruit on first cluster (g) & $21514.8^{* *}$ & 2848.7 \\
Plant dry weight (g) & $114770.9^{* * *}$ & 7314.2 \\
df & 3 & 12 \\
\hline
\end{tabular}

***,***Significant at $P \leq 0.05,0.01$, or 0.001 , respectively.

Table 4. Mean separation of variables identified as significant in Table 3.

\begin{tabular}{lccccc}
\hline Hotcap & $\begin{array}{c}\text { Plant ht at } \\
\text { first flower } \\
(\mathrm{cm})\end{array}$ & $\begin{array}{c}\text { Days to } \\
\text { first } \\
\text { ripe fruit }\end{array}$ & $\begin{array}{c}\text { No. fruit } \\
\text { set on first } \\
\text { cluster }\end{array}$ & $\begin{array}{c}\text { Plant } \\
\text { dry wt } \\
(\mathrm{g})\end{array}$ & $\begin{array}{c}\text { Total wt } \\
\text { fruit on } \\
\text { first cluster }(\mathrm{g})\end{array}$ \\
\hline Noncovered & 15.5 & 87 & 4.5 & 421 & 238 \\
Plastic jug & 16.5 & 92 & 1.5 & 81 & 83 \\
Plastic teepee & 23.3 & 76 & 2.5 & 55 & 98 \\
Wax paper & 20.0 & 80 & 2.3 & 128 & 94 \\
$\mathrm{~L} \mathrm{~S} \mathrm{D.05}$ & 2.7 & 10.0 & 1.9 & 117.6 & 82.2 \\
\hline
\end{tabular}

peratures $>30 \mathrm{C}$ on sunny days (Gent, 1990; Peterson and Taber, 1991).

Hotcaps were effective only during sunny periods, because there was little heat to be trapped from the ground due to the low soil temperatures. The heat-retention properties of PTs moderated daytime and nighttime temperatures more effectively than the other hotcap designs. Periodically ventilating the PTs by instead of water during the second year of the study effectively controlled algal growth. Although PTs are reusable, each unit requires cleaning between seasons. The unit cost of a PT was $\$ 3.00$ compared to $\$ 0.05$ for a WP unit. WP hotcaps were easy to install and disposable but provided less frost protection than PTs. PJs are not effective hotcaps because they are difficult to secure in the field, protect small plants only, and do not retain sufficient heat to provide frost protection.

\section{Literature Cited}

Bilderback, D. 1988. Cool-climate tactics. Rodale Organic Gardening 35(3):88-90.

Gent, M.P.N. 1990. Factors affecting harvest date of tomato grown under floating row cover. Applied Agr. Res. 5(2):112-1 18.

Peterson, R.H. and H.G. Taber. 1991. Tomato flowering and early yield response to heat buildup under rowcovers. J. Amer. Soc. Hort. Sci. 116:206-209.

Taber, H.G. 1983. Effect of plastic soil and plant covers on Iowa tomato and muskmelon production. Proc. Natl. Agr. Plastics Congr. 17:37-45.

Wells, O.S. 1990. Evolution of mulches and row covers for horticultural crop production. Proc. Natl. Symp. Stand Establishment Hort. Crops. p. 1-8.

Wells, O.S. and J.B. Loy. 1986. The current status of row cover use in the United States. Proc. Natl. Agr. Plastics Congr. 19:4-9.

Zink, F. W. 1954. Evaluation of plastic hotcaps on muskmelons. Proc. Amer. Soc. Hort. Sci. 64:315-321. 